\title{
OPINIÃO
}

\section{Brasil a caminho de um futuro melhor para todos?}

\author{
Adalmir Marquetti
}

RESUMO - O presente texto propõe que a combinação entre o crescimento econômico e o avanço do processo democrático pode resultar em uma trajetória de tipo high road para o Brasil, em que aumentos salariais se combinam com maior produtividade do trabalho e menor taxa de desemprego. A discussão das condições necessárias ao crescimento sustentável mostra que há possibilidades para a taxa de investimento continuar a aumentar, fazendo com que a renda per capita cresça a uma média anual próxima a 4\% nos anos vindouros. A distribuição desses ganhos para a população de baixa renda dependerá do processo democrático e da capacidade desses setores sociais se organizarem e proporem políticas públicas voltadas a atender as suas demandas.

Palavras chaves: Crescimento Econômico. Democracia. Economia Brasileira.

\section{INTRODUÇÃO}

Em 2008, a Nova Constituição, que marcou a plena retomada do processo democrático no país, completará 20 anos. Também em 2008, se confirmada à taxa prevista de crescimento, o Brasil completará cinco anos com aumento médio do PIB per capita próximo a $2,8 \%$ ao ano.

A Constituição de 1988 representa um marco histórico para a democracia brasileira. De um lado, ela reconheceu direitos econômicos dos segmentos de menor renda da população, de outro instituiu mecanismos que possibilitaram a participação popular na definição de políticas públicas. Por sua vez, a expansão do PIB per capita, ainda que reduzido quando comparado ao desempenho de outros países emergentes, é muito superior ao crescimento de $0,34 \%$ ao ano verificado entre 1980 e 2004.

O Brasil está vivendo um período que combina moderado crescimento econômico com o sistema democrático em pleno funcionamento. Esses períodos são incomuns na historia do país.

\footnotetext{
* Ph.D. em Economia. Professor do departamento de Economia, Pontifícia Universidade Católica do Rio Grande do Sul, PUC-RS, Av. Ipiranga 6681, Porto Alegre, RS, 90910-000, Brasil, Endereço Eletrônico: aam@pucrs.br
} 
O objetivo do presente texto é discutir questões ligadas à continuidade do crescimento econômico e como essa, associada ao avanço da democracia, pode resultar em um futuro melhor para todos os brasileiros.

Para tal, este trabalho foi dividido em duas sessões. A primeira analisará as condições necessárias para que o Brasil possa a se tornar um país com crescimento sustentável, e a segunda sessão fará uma exposição do regime democrático brasileiro vinculado ao crescimento da economia.

\section{CONDIÇÕES PARA O CRESCIMENTO SUSTENTÁVEL}

Inicialmente, discutem-se as condições necessárias para o país sustentar um crescimento médio da renda per capita próximo a 4\%, o desempenho de 2007, nos próximos anos. Essa é uma questão fundamental para o Brasil, que entre 1950 e 1973, na Idade Dourada do desenvolvimento capitalista, teve um crescimento médio do PIB per capita de 4,3\% ao ano. Por sua vez, no período pós 1980, chamado de Capitalismo Neoliberal, cresceu a um décimo desse valor. O gráfico abaixo releva o efeito que a queda no crescimento representou para o país; ele mostra a evolução do PIB per capita medido em paridade de poder de compras para o Brasil e a Coréia do Sul entre 1955 e 2004. Em 1980, o PIB per capita da Brasil era 50\% maior do que o da Coréia do Sul, em 2004 correspondia a somente $40 \%$ do PIB per capita coreano. Caso o Brasil tivesse mantido taxas de crescimento semelhantes às verificadas na Idade Dourada, a renda per capita atual seria similar a coreana.

GRÁFICO 1 - EVOLUÇÃO DO PIB PER CAPITA NO BRASIL E NA CORÉIA DO SUL - 1955-2004.

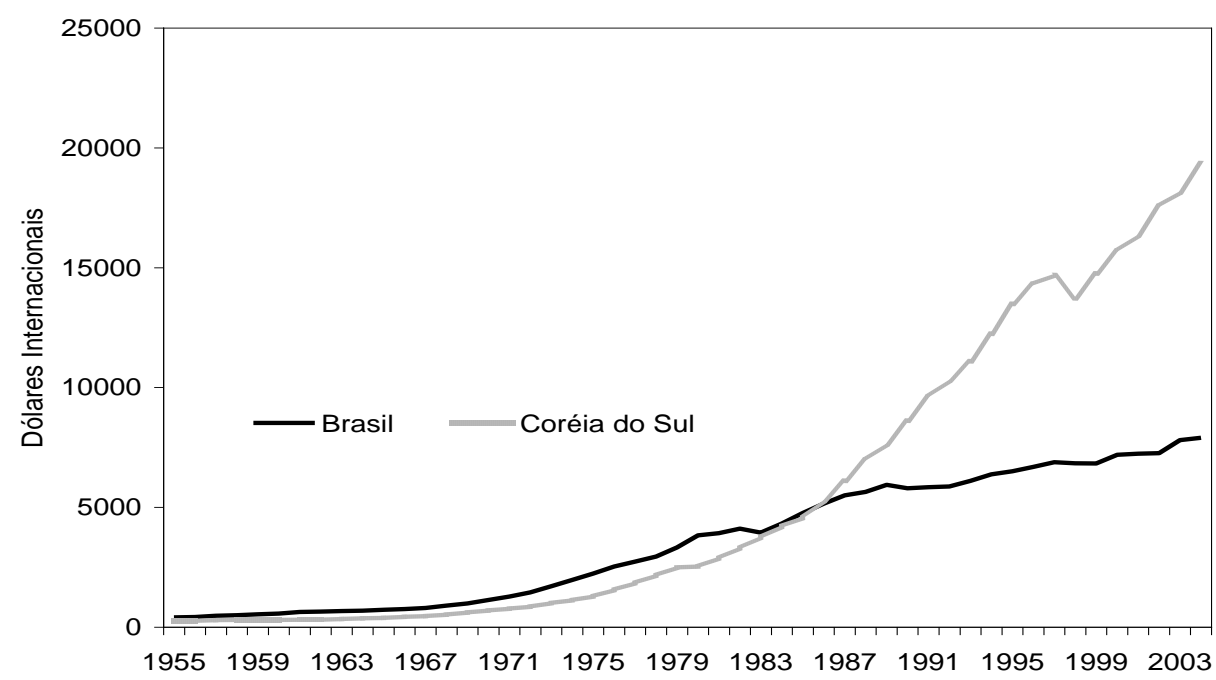

FONTE: HESTON, SUMMERS E ATEN (2006). 
A presente expansão econômica pode significar uma nova fase de crescimento sustentável para o país. Contudo, para que isso ocorra é necessário que a taxa de investimento em capital produtivo e infra-estrutura continue a se expandir, passando de 17,5\% para cerca de $20 \%$ ao ano. Mantida constante a produtividade do capital, essa é a taxa de investimento requerida para a renda per capita crescer próximo a $4 \%$ ao ano.

O Gráfico 2 mostra a evolução da taxa de investimento para a economia brasileira entre 1991 e 2007. Os dados da formação bruta de capital fixo e do PIB trimestral a preços correntes foram acumulados para quatro trimestres para, então calcular a razão entre as variáveis. A maior taxa de investimento foi de 21,5\% e ocorreu em 1994, no começo do Plano Real; a menor foi de 15,3\% nos quatro trimestres encerrados no primeiro trimestre de 2004 , quando passou a aumentar. Entre 2007 e 2006, o aumento na formação bruta de capital fixo foi de um ponto percentual do PIB, um montante de 65 bilhões de reais.

GRÁFICO 2 - TAXA DE INVESTIMENTO NA ECONOMIA BRASILEIRA - 1991-IV / 2007-IV

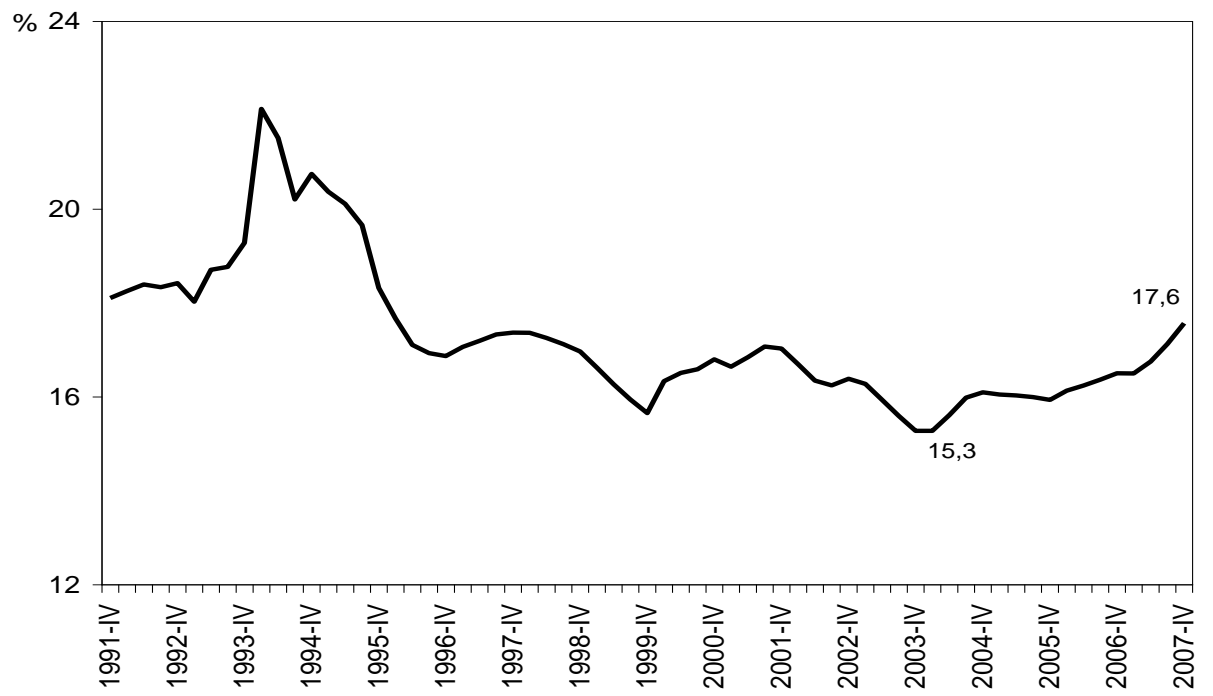

FONTE: IBGE (2008). Elaboração Própria.

Há quatro condições para que a taxa de investimento continue sua trajetória de crescimento e atinja os $20 \%$. A primeira é de que as empresas tenham expectativas de aumento da demanda para que concretizem seus planos de investimentos. Em outras palavras, o setor privado investirá se houver perspectivas de crescimento econômico.

O Gráfico 3 revela uma aceleração na taxa média de crescimento da economia brasileira que começou na virada da presente década. Em particular, chama atenção o fato dos vales dos ciclos de negócios ocorrerem a taxas cada vez maiores a partir de 1999. 


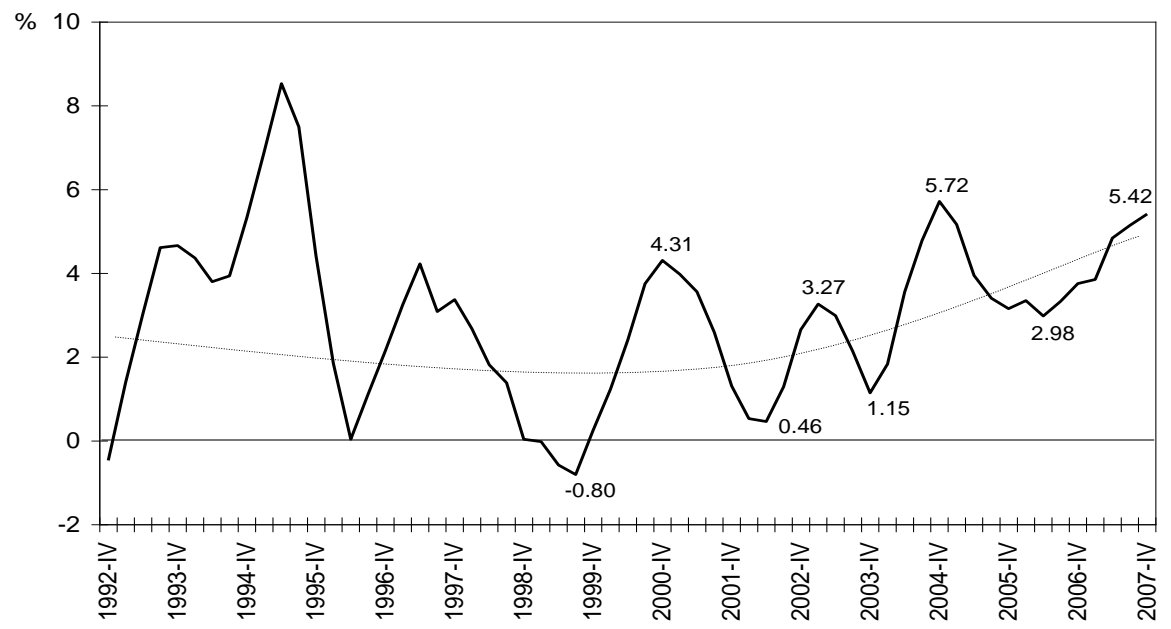

FONTE: IBGE (2008). Elaboração Própria.

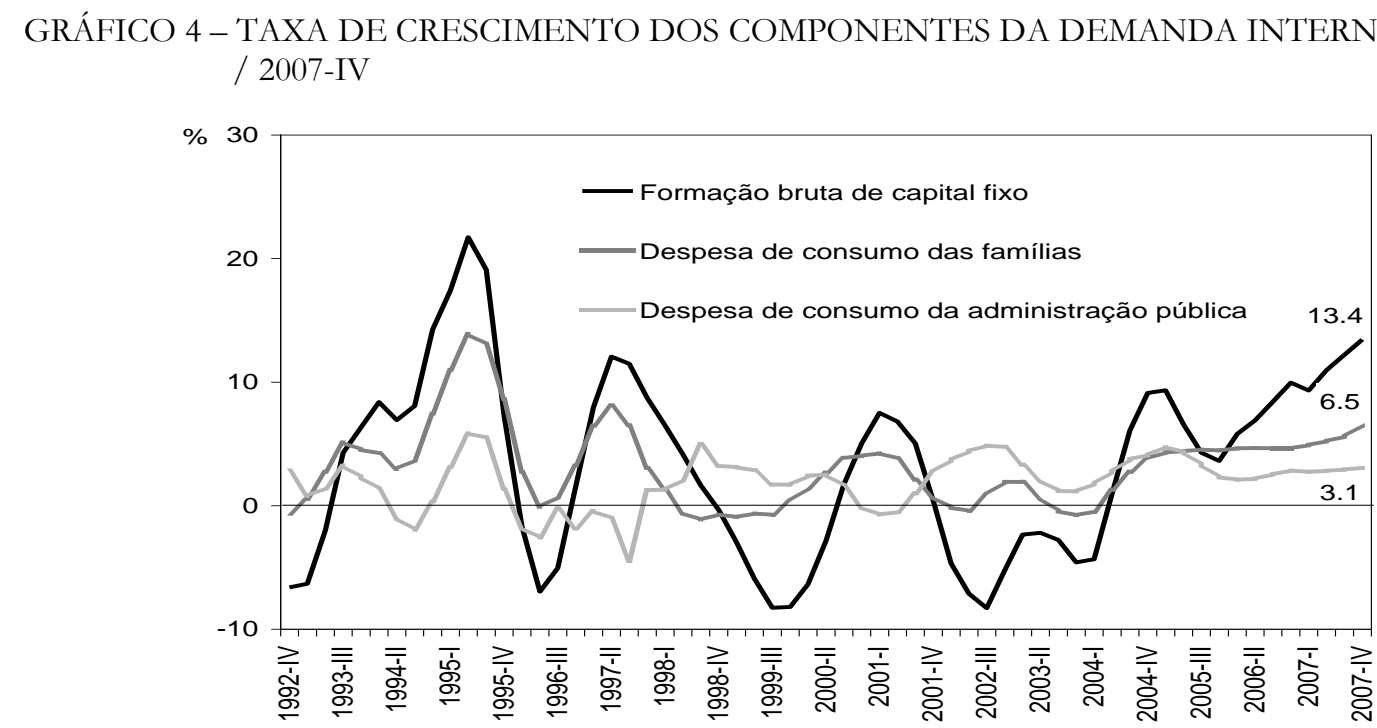

FONTE: IBGE (2008). Elaboração Própria.

A segunda condição é a flexibilização da política monetária com a redução da taxa de juros básica. Apesar da queda observada a partir de meados de 2005, a taxa Selic de 11,25\% ao ano é muito elevada.

O Brasil ocupa desde os anos 90 os primeiros lugares no ranking das taxas de juros reais mais elevadas do mundo. A sociedade brasileira, com a exceção do setor financeiro e de seus representantes, se pergunta qual é o motivo para o Brasil ter uma taxa de juro real tão alta.

A política monetária tem efeitos diretos sobre a política fiscal. Há a necessidade de fazer um enorme esforço com elevados superávits para fazer frente aos pagamentos dos juros da dívida. Ainda assim, há um déficit nominal com transferência de recursos da sociedade 
para o setor financeiro e rentistas. Aliás, embalada pelas elevadas taxas de juro, a dívida pública líquida passou de 31,1\% em 1994 para 44,9\% em 2007.

Outro efeito importante da política monetária é a valorização da taxa de câmbio. Com a diferença entre a taxa de juros paga pelos títulos do governo brasileiro e a taxa de juros internacional, ocorre a atração de capitais internacionais que provocam a valorização do real frente às demais moedas. Evidentemente, que há outros fatores que tem contribuído para a valorização real, como o saldo comercial e o enfraquecimento mundial do dólar. Contudo, a taxa de câmbio no Brasil passou de 3,53 reais por dólar em dezembro de 2002 para 1,77 reais por dólar em dezembro de 2007. No mesmo período, o peso argentino passou de 3,43 por dólar para 3,16.

A queda da taxa de juros abre espaço para a redução do superávit primário e maior investimento público, bem como reduz a atração de capitais internacionais de curto prazo, reduzindo o fôlego da valorização do real.

A terceira condição é a continuidade da situação relativamente confortável do país em relação às necessidades de recursos externos. Impulsionada inicialmente pela China, a economia mundial tem se expandido rapidamente ao longo da década. O Brasil se beneficiou com o aumento da quantidade exportada e preços internacionais muito favoráveis que permitiram elevados saldos comerciais e acumulação de reservas. O resultado foi que o Brasil tornou-se credor externo líquido em 2008, o que representa uma forte redução da vulnerabilidade do país aos choques internacionais.

Todavia, somente para o pagamento líquido de juros e de remessa de lucros e dividendos, o país precisa de aproximadamente 30 bilhões de dólares anuais. Além disso, a forte apreciação do real, bem como a crise do sub-prime e seus desdobramentos podem ter efeitos perversos e rápidos sobre a economia brasileira.

A quarta condição é a decisão do governo de dotar o país de um programa estratégico de desenvolvimento. O Estado brasileiro precisa voltar a funcionar como estado, tendo um papel indutor do crescimento econômico. O mercado por suas próprias forças realiza diversas tarefas, mas não é capaz de propiciar rápido crescimento econômico e distribuição de riqueza e renda. O Programa de Aceleração do Crescimento, o PAC, tem por objetivo investir R \$ 504 bilhões entre 2007 e 2010 nos setores de transporte, energia e infraestrutura urbana e social. Se concretizados, os investimentos atingirão 126 bilhões de reais por ano, valor suficiente para elevar a taxa de investimento a mais de $20 \%$ ao ano. Para atingir 
essa taxa em 2008, caso o PIB cresça a 5,3\%, é necessário aumentar o montante de formação bruta de capital fixo em 90 bilhões de reais a preços de 2007.

Logo, as condições para a renda per capita crescer de maneira sustentável próximo a 4\% estão parcialmente atendidas. Os maiores obstáculos advém da política monetária e dos possíveis efeitos que a crise sub-prime nos Estados Unidos terá sobre a economia mundial. Até o presente as repercussões sobre os países emergentes foram limitadas. Contudo, ainda há muita incerteza sobre a magnitude da crise e dos problemas que ela poderá causar.

\section{DEMOCRACIA, CRESCIMENTO E O FUTURO DO PAIÍS}

Após o processo de redemocratização nos anos 80, esse poderá ser o primeiro período com democracia e crescimento econômico sustentável. O que pode resultar em uma trajetória de crescimento do tipo high road em que o aumento dos salários reais e da produtividade do trabalho se combinam com elevação da demanda agregada e do emprego. Maior produção e a inserção internacional das empresas são compatíveis com direitos sociais dos trabalhadores e salários elevados.

Essa forma contrasta com o low road para o crescimento, em que a flexibilização do trabalho e a redução dos direitos dos trabalhadores faz com que as empresas ganhem competitividade devido aos baixos salários. O low road tem sido a trajetória proposta ao Brasil e aos países em desenvolvimento pelos defensores do neoliberalismo e, em particular, pelas agências internacionais. A importância do processo democrático para a uma trajetória do tipo high road fica clara ao se observar o gráfico abaixo, o qual apresenta a evolução do salário mínimo real entre 1947 e 2007.

GRÁFICO 5 - EVOLUÇÃO DO SALÁRIO MÍNIMO REAL

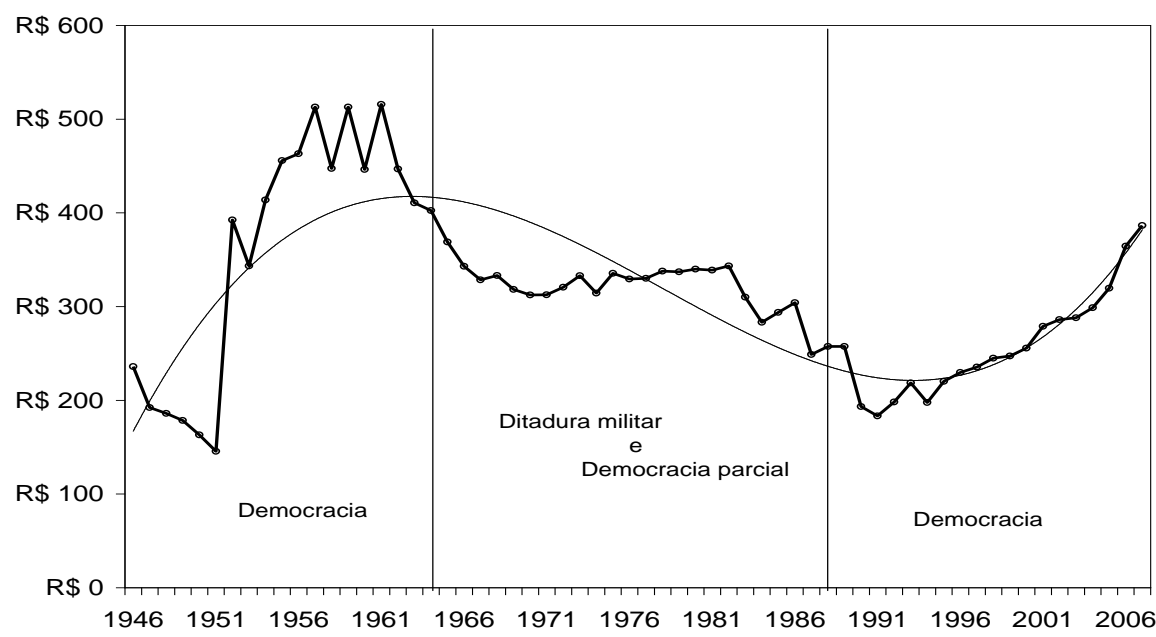

FONTE: IPEA (2008). Elaboração Própria.

140

Economia \& Tecnologia - Ano 04, Vol. 12 - Jan./Março de 2008 
Verifica-se que nos períodos democráticos houve uma tendência de aumento do salário mínimo real, enquanto no período da ditadura militar houve uma queda de seu valor. Além disso, observa-se que o salário mínimo real retomou a tendência de crescimento em 1991, após o processo de redemocratização e, ainda, no período de alta inflação.

A democracia possibilita maior organização dos setores sociais de menor renda e que esses apresentem suas demandas à sociedade e ao estado. A Constituição de 1988 instituiu mecanismos de democracia direta e também possibilitou que surgissem experiências de democracia participativa ao nível municipal. Entre esses cabe mencionar os conselhos municipais e, mais importante, as diversas experiências de orçamento participativo implementadas nas grandes cidades brasileiras. Aproximadamente, uma em cada três das cidades com população acima de 100 mil habitantes em 2000 utilizou o orçamento participativo na gestão 2001-2004 (MARQUET'TI et all, 2008).

O orçamento participativo (OP) é organizado a partir de assembléias públicas, nas quais os cidadãos realizam escolhas sociais, bem como elegem representantes que coordenam o processo de elaboração do orçamento. Os representantes eleitos, a partir de regras e das escolhas realizadas nas assembléias populares, definem as obras a serem realizadas nas diferentes regiões. As regras determinam que a distribuição dos investimentos priorize as regiões mais carentes das cidades. Por fim, é publicada a lista de obras e serviços que consta do próximo orçamento. Os cidadãos controlam a execução das obras definidas a partir dessa listagem.

Em muitas cidades, o OP abriu canais de participação para setores da sociedade que historicamente não tiveram voz na definição das políticas públicas e no controle das ações do Estado. O resultado foi a inversão das prioridades de políticas públicas, com os investimentos e a oferta de serviços públicos beneficiando as regiões mais carentes das cidades.

As experiências de OP mostram que o processo democrático na sociedade brasileira deve avançar para permitir que a população pobre tenha um papel relevante na definição das políticas públicas e no controle das ações do estado. (MARQUETTI et all, 2008)

Desse modo, esses setores sociais serão capazes de participar de forma efetiva na distribuição do aumento da renda que advém do crescimento econômico. A elevada e persistente desigualdade na distribuição da renda e da riqueza na sociedade brasileira decorre do poder das elites econômicas de influenciarem as políticas governamentais em seu benefício. 
O modelo neoliberal e a trajetória de low road representam justamente a redução da influência dos setores de menor renda nas instituições responsáveis pela definição da política econômica. O exemplo mais claro é o do Banco Central, o qual funciona de maneira independente da população de menor renda e dos trabalhadores e dependente dos interesses do capital financeiro. A política monetária tem sido um empecilho ao maior crescimento do país, com a taxa de juros funcionando como um poderoso instrumento de transferência de renda em favor dos detentores do capital financeiro e da dívida pública.

A construção de um futuro melhor em uma trajetória do tipo high road requer, de um lado, avanços no processo democrático com a adoção de mecanismos de controle da população de menor renda sobre as políticas públicas e, de outro, crescimento econômico. Sem essa combinação, provavelmente, um futuro melhor continuará longínquo para a maioria da população.

\section{REFERÊNCIAS}

HESTON, A.; SUMMERS, R.; ATEN, B. (2006). Penn world table version 6.2. Center for International Comparisons of Production, Income and Prices at the University of Pennsylvania.

IBGE. (2008). Contas Nacionais Trimestrais: outubro/dezembro 2007. Rio de Janeiro: IBGE.

IPEA. (2008). Ipeadata. Rio de Janeiro: IPEA. Disponível em http://www.ipeadata.gov.br. Acesso em: 20/3/2008.

MARQUETTI, A.; CAMPOS, G.; PIRES, R. (2008). Democracia participativa e redistribuição: análise de experiências de orçamento participativo. São Paulo: Editora Xamã. 